\title{
EFETIVAÇÃO DO DIREITO À SAÚDE: AMPLIAÇÃO DO DEBATE E RENOVAÇÃO DA AGENDA
}

Realization of the right to health: broadening of the debate and renewal of the agenda

${ }^{1}$ Faculdade de Direito, Universidade de São Paulo. São Paulo/SP, Brasil.

${ }^{2}$ Núcleo de Estudos e Pesquisas em Direito Administrativo Democrático, Faculdade de Direito, Universidade de São Paulo. São Paulo/SP, Brasil.

Correspondência: Gustavo Justino de Oliveira. E-mail: gjoliveira@usp.br.

Recebido em:15/06/2015. 


\section{Introdução}

Refletir e debater sobre os aspectos teóricos e práticos da efetivação do direito fundamental à saúde no Brasil revela-se recorrente nas agendas sociopolítica e acadêmica do país.

Entretanto, mais do que uma mera discussão temática, trata-se de um desafio permanente, (auto)renovável na mesma velocidade, proporção e intensidade com que Estado, mercado, sociedade civil e cidadãos presenciam as fortes tendências e transformações vivenciadas por todos e cada um de nós na árdua tarefa de viver e sobreviver com dignidade em um mundo de crescente hostilidade.

Por isso, endereçar e enfrentar os contornos da efetivação do direito fundamental à saúde, na forma em que este direito sensível está configurado no ordenamento jurídico e no sistema administrativo brasileiros, é, por sua imprescindibilidade à vida humana, um dever permanente.

Nesse viés, à academia cumpre o relevante papel de manter em seu radar investigativo as conquistas e as mazelas do setor, propondo análises e identificando soluções coerentes para os problemas existentes, antevendo tecnologias sociojurídicas adequadas para ensejar o permanente aperfeiçoamento das diversas instâncias competentes a realizar este que talvez seja o direito mais intrínseco à realização e consolidação da dignidade dos indivíduos.

\section{Ampliação do debate e renovação da agenda: referências contemporâneas para o enfrentamento da efetividade do direito à saúde}

Antes de apresentar os excelentes trabalhos científicos que compõem este Tema em Debate, pretendo estabelecer à luz do direito público brasileiro - mas, apoiado em uma visão interdisciplinar - um elenco de cinco referências contemporâneas que, no meu entender, representam conditio sine qua non para a compreensão das novas fronteiras nas quais deve a academia adentrar para prosseguir em análises percucientes e pragmáticas quando mirar a efetivação do direito à saúde como objeto de investigação.

\section{Ainda o déficit de efetividade e a Constituição Federal de 1988}

Sob o ponto de vista da realização dos ditames e diretrizes fundamentais da Constituição Federal de 1988, vivemos ainda um ambiente em que existe déficit de efetividade de uma série de direitos, não sendo o direito fundamental à saúde uma exceção.

Obviamente, houve grandes avanços no setor sanitário nas últimas décadas, notadamente a partir da poderosa e exitosa estruturação do Sistema Único de Saúde (SUS), carregado de uma principiologia material coerente, erigido sobre uma base 
fundante que visa a proporcionar aos cidadãos o acesso universal a ações e serviços integrantes do direito fundamental à saúde.

Todavia, a noção de um "sistema de saúde" traz em si um sentido de "obra inacabada", porque em permanente evolução, destinada a satisfatória e continuadamente atender a todas as necessidades imanentes àquilo que o sistema invoca como sendo "direito fundamental à saúde". Ademais, a própria configuração jurídico-constitucional do direito fundamental à saúde revela-se uma tarefa dinâmica e mutável, nunca sedimentada ou restrita a um dado momento histórico, pois deve acompanhar as inovações tecnológicas e fazer frente aos novos desafios físicos e mentais aos quais o próprio ser humano é chamado a corresponder no mundo contemporâneo.

Para que esse déficit de efetividade seja devidamente enfrentado e razoavelmente suprido, não podemos nos bastar exclusivamente com a edição de leis exigidas pelo texto constitucional para regulamentar inúmeras facetas do direito fundamental à saúde, mas igualmente demandar pela real e ponderada atuação do Poder Executivo e do Poder Judiciário ${ }^{1}$, cada qual em seu âmbito de competência, para fazer valer aquilo que o constituinte esculpiu como sendo essência e substância do direito à saúde.

Passados quase 30 anos da promulgação da Constituição de 1988, podemos dizer que muito evoluímos, mas ainda há consideráveis lacunas que devem ser preenchidas, sobretudo quando estão em foco as relações intersetoriais entre os poderes neste campo temático. Essa intersetorialidade cooperativa há de ser constantemente calibrada, sob pena de comprometimento do ciclo de efetividade do direito à saúde - que depende intensamente da boa articulação entre Legislativo, Executivo e Judiciário ${ }^{2}$, em um equilíbrio de forças difícil de ser atingido e fácil de ser instabilizado.

\section{Responsividade e democraticidade nas políticas públicas da saúde: eficiência e legitimidade sanitárias}

Devemos considerar que as políticas públicas da área da saúde devem ser altamente responsivas e democráticas - atendendo aos ditames constitucionais e materialmente alinhadas às atuais e reais necessidades da população, contando

\footnotetext{
${ }^{1}$ O fenômeno da judicialização das políticas públicas no Brasil, expressado por meio de um maior ativismo do Poder Judiciário, reforça-se sobremaneira no último decênio, iniciando seu ciclo justamente a partir de julgamentos de litígios envolvendo a busca da efetivação do direito à saúde, em suas mais diferentes projeções. A propósito, ver COELHO, Inocêncio Mártires. Apontamentos para um debate sobre o ativismo judicial. Revista Brasileira de Políticas Públicas, Brasília, v. 5, n. esp. p. 2-22, 2015. Defendendo o protagonismo do Legislativo frente à realização dos direitos, conferir WALDRON, Jeremy. The core ofthe case against judicial review. The Yale Law Jornal, v. 115, 2006. http://dx.doi.org/10.2307/20455656.

${ }^{2}$ Por exemplo, conferir interessante caso da relação Legislativo-Executivo analisado por ALMEIDA JÚNIOR, João Cauby de. Arenas de produção de políticas públicas: a nova política nacional de saúde mental. Revista Direito GV, São Paulo, v. 9, n. 2, p. 659-680, jul./dez. 2013. http://dx.doi.org/10.1590/S180824322013000200012.
} 
inclusive com sua participação ativa no processo de formulação e implementação dessas políticas ${ }^{3}$.

Aqui, os desafios para a efetividade dessas políticas não se encontram unicamente em aspectos técnicos que devem ser permanentemente realizados e internalizados por meio de ações e serviços de saúde. Mais do que isso, os entes públicos competentes para o desenho e execução dessas políticas públicas de saúde têm o dever de concomitantemente considerarem critérios de eficiência e de legitimidade aplicáveis ao setor.

A eficiência na saúde pode ser traduzida no atendimento de critérios de qualidade, atualidade e celeridade na realização das ações e na prestação dos serviços; na boa aplicação dos recursos públicos na gestão da saúde; na geração de indicadores de desempenho para fins de avaliação do grau de efetividade das políticas e de seu impacto na área temática em que incidem; na observância de determinados padrões por todos os órgãos públicos competentes e por todos os demais agentes privados envolvidos na consecução das tarefas sanitárias; entre outros aspectos.

Portanto, a efetividade do direito à saúde há de perpassar pela qualidade das ações e dos serviços prestados, considerado inefetivo o direito, se a ação ou o serviço não foi realizado com qualidade. Nesse diapasão, eventuais omissões ou deficiências na execução das tarefas podem gerar indenizações a serem arcadas pelos cofres públicos, pagas a todo aquele que sofrer um dano em decorrência de um serviço de saúde que não foi prestado, que foi prestado tardiamente ou que foi prestado com falta de rigor técnico.

Por outro lado, a legitimidade na saúde diz respeito à obrigatória participação da população em todo o ciclo formador da política pública setorial e, atualmente, deve ir muito além da representação e atuação dos Conselhos de Saúde, já internalizados em todos os níveis federativos ${ }^{4}$. Outros canais sociais participativos devem ser estabelecidos pelo poder público, não somente por meio do Poder Executivo, mas também pelo Legislativo e pelo Judiciário. Felizmente, isso já vem acontecendo ${ }^{5}$, mas devemos trilhar o caminho da disseminação de institutos participativos na área da saúde, sob pena de o direito à saúde restar inefetivo por ausência de legitimidade.

\footnotetext{
${ }^{3}$ Acerca do tema, e sobre o protagonismo do Executivo na realização dos direitos sociais, ver nossa Administração pública democrática e efetivação de direitos fundamentais. In: OLIVEIRA, Gustavo Justino de. Direito administrativo democrático. Belo Horizonte: Fórum, 2010.

${ }^{4}$ Sobre a problemática do modelo de representação eleitoral da sociedade no âmbito dos conselhos de saúde, ver BISPO JÚNIOR, José Patrício; GERSCHMAN, Sílvia. Legitimidade da representação em instâncias de participação social: o caso do Conselho Estadual de Saúde da Bahia. Caderno de Saúde Pública, Rio de Janeiro, v. 31, n. 1, p. 183-193, jan. 2015. http://dx.doi.org/10.1590/0102-311X00086214.

${ }^{5}$ Ver audiência pública realizada pelo Supremo Tribunal Federal para discutir a judicialização do direito à saúde, no âmbito do julgamento do Ag Reg. na Suspensão da Tutela Antecipada n. 175-CE, Tribunal Pleno, Rel. Min Gilmar Mendes, j. 17.03.2010, DJU 30.04.2010.
} 
Assim, efetivo será o direito à saúde cuja política pública correspondente seja responsiva e democrática, recentralizando seu foco no cidadão - o titular do direito, que precisa ser ouvido e atendido em seus anseios existenciais - e parametrizada por critérios de dignidade, eficiência e legitimidade.

\section{Governança sanitária: intersetorialidade e otimização das ações na saúde}

A governança sanitária há de merecer especial atenção na seara da efetividade do direito à saúde. A repartição de competências entre os entes federados e a transversalidade do direito à saúde; as relações intersetoriais dos órgãos públicos encarregados das tarefas do sistema; a transparência e o controle social e democrático das ações, dos serviços e dos recursos empregados; a tomada das decisões e o escalonamento dos níveis e instâncias integrantes do sistema; o combate às sobreposições de competências e ao desperdício de recursos; as relações eficientes dos atores e agentes públicos com o mercado e com a sociedade para a boa prestação dos serviços e realização das ações de saúde; a participação comunitária como diretriz do sistema, entre outros aspectos, compõem referências que visam a expressar e sedimentar a governança sanitária, imprescindível para que o complexo e policêntrico sistema de saúde brasileiro consiga alcançar níveis ótimos de realização das ações e prestações dos serviços a ele imanentes, conquistando a efetividade do direito à saúde.

\section{Ainda a governança sanitária: modelos de gestão colaborativos e parceirização público-privada na saúde}

Ainda vinculada à governança sanitária, está a escolha adequada e motivada do(s) melhor(es) modelo(s) de gestão para a execução das ações e da prestação dos serviços, com a necessária conjugação ${ }^{6}$ dos recursos materiais e humanos dos órgãos públicos coordenadores do sistema com aqueles recursos e potenciais existentes no mercado e na sociedade civil, em uma visão colaborativa e parceirizada.

É fato que atualmente os recursos materiais à disposição dos órgãos públicos gerenciadores do sistema de saúde tornam-se cada vez mais escassos - considerando, por exemplo, que devem atender a uma população cada vez mais numerosa, a qual se encontra em acelerado processo de envelhecimento, e assim por diante, numa lista interminável de motivos de difícil enfrentamento.

Esperar que os órgãos públicos isoladamente cumpram esse desiderato não só é uma expectativa inatingível, como também anacrônica. As possibilidades de êxito no longo percurso de efetivação do direito à saúde residem nessa dimensão colaborativa e concertada da governança sanitária, na busca da saúde como

\footnotetext{
${ }^{6}$ Nessa matéria, ver acórdão paradigmático do Tribunal de Contas da União, sobre Transferência do Gerenciamento de Serviços Públicos de Saúde a Organizações Sociais, TC 018.739/2012-1, Acórdão n. 3239/2013-TCU-Plenário, Rel. Min Walton Alencar Rodrigues, j. em 27.11.2013.
} 
elemento central do bem-estar social, entendida como interesse comum do público e do privado 7 . E a parceirização entre Estado e organizações da sociedade civil - por meio de termos de parceria, contratos de gestão, termos de fomento e termos de colaboração - revela-se inestimável ferramenta de gestão para que se atinjam os fins previstos pela política sanitária.

\section{Combate à inequidade sanitária e aos riscos de exclusão: equalizando a questão social da saúde a partir das desigualdades crônicas}

Por fim, embora o Brasil figure em posição de destaque no cenário latino-americano - provavelmente devido às recentes conquistas angariadas com o SUS ${ }^{8}$-, persiste ainda um corrosivo cenário de inequidade sanitária, concebida pela Organização Mundial da Saúde (OMS) como "diferenças injustas e evitáveis em matéria de saúde e de prestação de serviços de atenção sanitária".

Essa assimetria no tratamento entre os indivíduos, agravada por um sistema que se pretende universal, perpetua um generalizado ambiente de exclusão e de despertencimento dos mais vulneráveis, acarretando trágicas perdas para a cidadania, muitas de difícil ou impossível reparação. Por isso, discutir efetividade do direito à saúde obrigatoriamente deve perpassar pela procura de soluções que fortaleçam iniciativas destinadas a combater as injustiças e a exclusão sanitária, equalizando a questão social da saúde com a necessidade de superação das desigualdades decorrentes de inequidades geradas no âmbito do próprio sistema.

\section{As relevantes contribuições dos autores ao Tema em Debate}

Todos os trabalhos científicos selecionados para o presente Tema em Debate relacionam-se com uma ou mais das referências contemporâneas acima apontadas e, por isso, configuram atuais e relevantes contribuições para o aprofundamento dos debates sobre a efetivação do direito à saúde.

Balestra Neto enfrenta o tema da judicialização do direito à saúde, colocando em perspectiva histórica e evolutiva a jurisprudência do Supremo Tribunal Federal e do Superior Tribunal de Justiça que se formou ao longo dos últimos anos na resolução de litígios cujo objeto era a (não) efetivação do direito à saúde. $\mathrm{O}$ autor classifica os precedentes judiciais em fases específicas, a partir de critérios materiais e cronológicos, resgatando a linha do tempo e a ratio das decisões que culminam em posicionamentos mais conciliadores na

\footnotetext{
${ }^{7}$ Sobre o tema da governança sanitária, ver KICKBUSCH, Ilona; GLEICHER, David. Governance for health in the 21st century. Copenhagen: World Health Organization, 2012.

${ }^{8}$ Ver WORLD HEALTH ORGANIZATION. World Health Statistics, 2015.

${ }^{9}$ ORGANIZACIÓN MUNDIAL DE LA SALUD. Estadísticas Sanitarias Mundiales, 2014. p. 153.
} 
análise das pretensões dos titulares dos direitos e do poder público a quem cabe efetivá-los. Nas palavras do autor, “a jurisprudência dominante nos dois tribunais superiores tem observado os critérios postos pelas políticas públicas sanitárias estabelecidas pelo Estado brasileiro, sem se olvidar de conceder tutelas jurisdicionais especiais para situações específicas e graves, ponderando no caso concreto o direito do cidadão de ter providas suas necessidades sanitárias e os critérios da Administração Pública para o fornecimento das prestações materiais em saúde" 10 .

Apoiada na Teoria dos Sistemas Sociais de Niklas Luhmann, Vial constrói destemido e inovador tratamento científico da saúde, sustentando que "a sociedade, como um sistema social, é composta por subsistemas e constituída por comunicações $(. . .)^{11}$ " e que "a saúde se constitui em um sistema social diferenciado funcionalmente"12. Para a autora, "a teoria nos oferece pressupostos capazes de, diante do processo evolutivo, sustentar que a saúde aprimorou suas comunicações e estruturou-se como um subsistema social, ou em sistema social, diante das complexidades advindas da própria sociedade"13.

Araújo empreende uma análise empírica e crítica do apaixonante tema das relações público-privadas no financiamento da saúde e em seus novos modelos de gestão. A autora lança olhares agudos sobre o modelo neodesenvolvimentista brasileiro, tecendo considerações importantes sobre o fenômeno da privatização da saúde e a centralidade da questão social. Para a autora, "ficam latentes os limites que o modo de produção capitalista coloca a qualquer possibilidade de desenvolvimento, seja destinado ao humano em detrimento à acumulação do capital, seja na saúde, na educação (...). Lembrando ainda que as desigualdades sociais são geradas pelo capitalismo, e não pela sua ausência, como tentam sugerir os defensores do neodesenvolvimentismo ${ }^{14}$ ".

\section{Considerações finais}

É possível notar que a condição humana torna-se acentuadamente difícil nos tempos atuais, sobretudo se considerarmos que mudanças das mais diversas ordens sucedem-se de forma caótica e acelerada, em um cenário repleto de incertezas e inconstâncias.

10 BALESTRA NETO, Otavio. A jurisprudência dos tribunais superiores e o direito à saúde - evolução rumo à racionalidade. Revista de Direito Sanitário, São Paulo, v. 16, n. 1, mar./jun. 2015, p. 87-111. http://dx.doi. org/10.11606/issn.2316-9044.v16i1p87-111.

${ }^{11}$ VIAL, Sandra Regina Martini. Construção do sistema social da saúde a partir da Teoria Sistêmica de Niklas Luhmann. Revista de Direito Sanitário, São Paulo, v. 16, n. 1, mar./jun. 2015, p. 112-127. http://dx.doi. org/10.11606/issn.2316-9044.v16i1p112-127.

12 Id. Ibid., p. 120.

${ }^{13}$ Id. Ibid., p. 126.

${ }^{14}$ ARAUJO, Isabela Maria Mendes de. Direito à saúde: aspectos do modelo neodesenvolvimentista brasileiro e da privatização da saúde. Revista de Direito Sanitário, São Paulo, v. 16, n.1, mar./jun. 2015, p. $128-145$. http://dx.doi.org/10.11606/issn.2316-9044.v16i1p128-145. 
No Brasil, diferentemente de países mais desenvolvidos, tais mutações não estão ainda inseridas em um contexto bem acabado de (i) justiça e equidade sociais, (ii) igualdade de tratamento jurídico-substancial e (iii) efetivo acesso universal ao catálogo constitucionalizado dos direitos sociais dos cidadãos - circunstâncias que afetam negativamente todos os membros da sociedade, especialmente os menos favorecidos.

Por isso, discutir efetividade do direito à saúde nos dias atuais implica renovar a agenda investigativa por meio da verticalização do debate, a partir de novos referentes, como (a) déficit de efetividade e Constituição de 1988, (b) responsividade e democraticidade nas políticas públicas da saúde, (c) governança sanitária, na dupla dimensão de intersetorialidade e otimização das ações na saúde, e modelos de gestão colaborativos e parceirização público-privada, e (d) combate à inequidade sanitária e análise da ameaça dos riscos de exclusão.

Os artigos que compõem o Tema em Debate do presente número da Revista de Direito Sanitário vão ao encontro desses desafios e expressam contribuições relevantes para a atualização e ampliação do debate sobre a efetividade do direito à saúde no Brasil.

\section{Referências}

ALMEIDA JÚNIOR, João Cauby de. Arenas de produção de políticas públicas: a nova política nacional de saúde mental. Revista Direito GV, São Paulo, v. 9, n. 2, p. 659-680, jul./dez. 2013. http://dx.doi.org/10.1590/S1808-24322013000200012.

ARAUJO, Isabela Maria Mendes de. Direito à saúde: aspectos do modelo neodesenvolvimentista brasileiro e da privatização da saúde. Revista de Direito Sanitário, São Paulo, v. 16, n. 1, mar./jun. 2015, p. 128-145. http://dx.doi.org/10.11606/issn.2316-9044.v16ilp128-145.

BALESTRA NETO, Otavio. A jurisprudência dos tribunais superiores e o direito à saúde - evolução rumo à racionalidade. Revista de Direito Sanitário, São Paulo, v. 16, n. 1, mar./jun. 2015, p. 87-111. http://dx.doi.org/10.11606/issn.2316-9044.v16i1p87-111.

BISPO JÚNIOR, José Patrício; GERSCHMAN, Sílvia. Legitimidade da representação em instâncias de participação social: o caso do Conselho Estadual de Saúde da Bahia. Caderno de Saúde Pública, Rio de Janeiro, v. 31, n. 1, p. 183-193, jan. 2015. http://dx.doi.org/10.1590/0102$311 X 00086214$.

COELHO, Inocêncio Mártires. Apontamentos para um debate sobre o ativismo judicial. Revista Brasileira de Políticas Públicas, Brasília, v. 5, n. esp. p. 2-22, 2015.

KICKBUSCH, Ilona; GLEICHER, David. Governance for health in the 21st century. Copenhagen: World Health Organization, 2012.

OLIVEIRA, Gustavo Justino de. Administração pública democrática e efetivação de direitos fundamentais. In: OLIVEIRA, Gustavo Justino de. Direito administrativo democrático. Belo Horizonte: Fórum, 2010. 
ORGANIZACIÓN MUNDIAL DE LA SALUD. Estadísticas Sanitarias Mundiales, 2014.

VIAL, Sandra Regina Martini. Construção do sistema social da saúde a partir da Teoria Sistêmica de Niklas Luhmann. Revista de Direito Sanitário, São Paulo, v. 16, n. 1, mar./jun. 2015, p. 112-127. http://dx.doi.org/10.11606/issn.2316-9044.v16ilp112-127.

WALDRON, Jeremy. The core ofthe case against judicial review. The Yale Law Jornal, v. 115, 2006. http://dx.doi.org/10.2307/20455656.

WORLD HEALTH ORGANIZATION. World Health Statistics, 2015.

Gustavo Justino de Oliveira - Professor Doutor de Direito Administrativo da Faculdade de Direito da Universidade de São Paulo. Coordenador do Núcleo de Estudos e Pesquisas em Direito Administrativo Democrático da Faculdade de Direito da Universidade de São Paulo. São Paulo/SP, Brasil.E-mail: gjoliveira@usp.br. 